\title{
Correction to: A Preliminary Toxicology Study on Eco-friendly Control Target of Spodoptera frugiperda
}

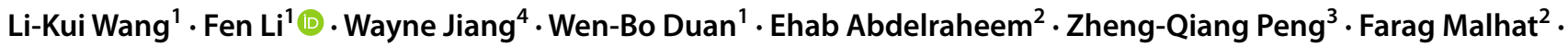 \\ Shao-Ying $\mathrm{Wu}^{1}$
}

Accepted: 2 February 2021 / Published online: 20 February 2021

๑) Springer Science+Business Media, LLC, part of Springer Nature 2021

\section{Correction to:}

Bulletin of Environmental Contamination and Toxicology https://doi.org/10.1007/s00128-020-03044-z

The original version of the article unfortunately contained a mistake in first author. Li-Kui Wang and Fen Li are co-first author in this paper. The correct lineage is given below.

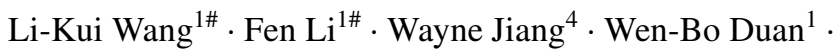
Ehab Abdelraheem ${ }^{2} \cdot$ Zheng-Qiang Peng $^{3} \cdot$ Farag Malhat $^{2 *}$ - Shao-Ying $\mathrm{Wu}^{1 *}$

\#Authors contributed equally to this study.

*Corresponding authors contributed equally to this study.

This has been corrected with this erratum.

Li-Kui Wang and Fen Li sharing are co-first authors and contributed equally to this study.

Farag Malhat and Shao-Ying Wu are corresponding authors and contributed equally to this study.

The original article can be found online at https://doi.org/10.1007/ s00128-020-03044-z.

Farag Malhat

farag_malhat@yahoo.com

$\triangle$ Shao-Ying Wu

wsywsy6000@hainanu.edu.cn

1 College of Plant Protection, Key Laboratory of Green Prevention and Control of Tropical Plant Diseases and Pests, Hainan University, Ministry of Education, 570228 Haikou, China

2 Pesticide Residues and Environmental Pollution Department, Central Agricultural Pesticide Laboratory, Agricultural Research Center, 12618, Dokki, Giza, Egypt
Publisher's Note Springer Nature remains neutral with regard to jurisdictional claims in published maps and institutional affiliations.
3 The Ministry of Agriculture and Rural Affairs Key Laboratory of Integrated Pest Management of Tropical Crops, Environment and Plant Protection Institute, Chinese Academy of Tropical Agricultural Sciences, 571101 Haikou, China

4 Department of Entomology, Michigan State University, 48824 East Lansing, MI, USA 